\title{
Oxygen Concentration during Reperfusion in Mitral Valve Surgery
}

\author{
Ranjith Karthekeyan, Mahesh Vakamudi, Sandeep Bangale, Rajeshkumar Kodali, \\ Kamalakannan Sambandham, N. Hemanand, Sushma Nandipati, Soumya \\ SRMC \& RI-Sri Ramachandra Medical College \& Research Institute, Chennai, India \\ Email: ranjithb73@gmail.com
}

Received September 7, 2013; revised November 7, 2013; accepted November 14, 2013

Copyright (C) 2013 Ranjith Karthekeyan et al. This is an open access article distributed under the Creative Commons Attribution License, which permits unrestricted use, distribution, and reproduction in any medium, provided the original work is properly cited.

\begin{abstract}
Background: By lowering the oxygen fraction of the reperfusate, the reactive oxygen-derived free radicals can be reduced thus facilitating myocardial recovery during weaning from cardiopulmonary bypass and after surgery. Materials \& Methods: Thirty patients undergoing mitral valve replacement were randomly exposed to an oxygen fraction of 0.7 (hyperoxic, $\mathrm{n}=15$ ) or 0.5 (normoxic, $\mathrm{n}=15$ ) during reperfusion. Hemodynamic variables, number of patients requiring additional inotropes and who developed new arrhythmia, duration of ventilation and intensive care unit stay, arterial blood gas and renal function were measured. Results: The demographic data, duration of cardiopulmonary bypass, aortic cross clamp time, duration of mechanical ventilation, intensive care unit stay, additional inotropes, arrhythmia after reperfusion and renal function were similar in both groups. Arterial blood gas analysis was not significantly different, except for the low oxygen partial pressure in the normoxic group during reperfusion. With regard to hemodynamic variables, mean arterial pressure of the hyperoxic group was higher one hour after the cross clamp release. Hemodynamic variables were comparable in all other time periods. Conclusion: By reducing the oxygen concentration during reperfusion, the clinical outcomes in terms of inotropes usage, new arrhythmia after reperfusion, renal function, duration of ventilation and intensive care unit stay were not significantly altered.
\end{abstract}

Keywords: Cardiopulmonary Bypass; Normoxic; Hyperoxic; Oxygen; Reperfusion; Free Radicals

\section{Background}

Oxygen tension during reperfusion in cardiopulmonary bypass plays a major role in ischemic-reperfusion injury. Cardiopulmonary bypass is commonly instituted in a hyperoxic fashion where the arterial oxygen tension is 300 to $400 \mathrm{~mm}$ of $\mathrm{Hg}$. The overproduction of oxygenderived free radicals and cytosolic calcium are the major causes for ischemic-reperfusion myocardial injury. Consequences of reperfusion injury include ventricular fibrillation, myocardial stunning and loss of intracellular proteins. Thus, reducing reperfusion injury is very important in improving prognosis [1]. By lowering the oxygen fraction of the reperfusate, the reactive oxygen-derived free radicals which are the main causes of reperfusion myocardial injury can be reduced thus facilitating myocardial recovery during weaning from cardiopulmonary bypass and after surgery.

\section{Introduction}

During cardiopulmonary bypass, the myocardium is da- maged not only by ischemic injury but also by reperfusion injury. Administering oxygen during reperfusion may be a "double-edged sword" [2]. In theory, increased availability of oxygen might increase reactive oxygen species production and thus aggravate the reperfusion injury. Further, it has been shown that hyperoxia induces coronary vasoconstriction and decreases coronary flow in both healthy volunteers and patients with coronary artery disease [3]. On the other hand, studies in different models have suggested that normoxia during reoxygenation of the hypoxic or cardioplegic heart reduces reperfusion injury [4-6]. Hypoxic or controlled reperfusion alleviates post-ischemic injury in skeletal muscle [7] and stomach [8]. A recent editorial in the British Medical Journal stated that "the potential dangers of hyperoxia need to be recognized," and that "oxygen therapy remains a cornerstone of modern medical practice. To further quantify the risks associated with hyperoxia, more trials are needed" [9]. In cardiac surgery using cardiopulmonary bypass and cardioplegia, there is a postcardioplegic reperfusion of 
the ischemic myocardium. We hypothesized that hyperoxia at the time of reperfusion might increase ischemia/ reperfusion injury. So we reduced the oxygen concentration to normoxia during reperfusion.

\section{Aim}

To evaluate the effect of arterial oxygen tension during reperfusion on perioperative outcomes in patients undergoing mitral valvular replacement by an analysis of hemodynamic variables, inotropes usage, renal function, duration of ventilation and intensive care unit stay.

\section{Materials and Methods}

This is a prospective randomized study of 30 consecutive patients undergoing mitral valve replacement. The patients were divided into 2 groups comprising of 15 patients in each group. The age range was from 18 - 50 years. The study was approved by the institutional review board and informed consent was obtained from all patients. Patients with severe mitral stenosis (valve area less than $1 \mathrm{~cm}^{2}$ ) and moderate to severe pulmonary artery hypertension were included in the study.

The exclusion criteria included a left ventricular ejection fraction less than $40 \%$, right ventricular dysfunction, rhythm other sinus, evidence of a coagulopathy, chronic lung disease, liver and kidney disease, previous heart surgery, mechanical support during weaning of cardiopulmonary bypass and oxygen partial pressure of less than $75 \mathrm{~mm}$ of $\mathrm{Hg}$ with an inspired oxygen fraction of 0.4 after induction.

Patients were randomly allocated to 2 groups based on the inspired oxygen concentration at the time of last reperfusion after the release of aortic cross clamp. Hyperoxic group received an inspired oxygen concentration of 0.7. Normoxic group received an inspired oxygen concentration of 0.5 . Only the perfusionist was aware of the patient group. Anesthesia was induced with midazolam $0.05 \mathrm{mg} / \mathrm{kg}$, fentanyl $2 \mu \mathrm{g} / \mathrm{kg}$, etomidate $0.2 \mathrm{mg} / \mathrm{kg}$ and vecuronium bromide $0.3 \mathrm{mg} / \mathrm{kg}$. After tracheal intubation, the lungs were ventilated with a tidal volume of $5-8$ $\mathrm{ml} / \mathrm{kg}$ at a rate of $12-14$ breaths $/ \mathrm{min}, \mathrm{a} \mathrm{FiO} 2$ of 0.5 and maintained with sevoflurane $1 \%-2 \%$. Monitors included electrocardiogram, pulse oximetry, invasive arterial pressure, central venous pressure, temperature, bispectral index, urine output and tranesophageal echocardiogram. Arterial blood gas was done as an when required.

The bypass circuit was primed with ringer lactate to make a priming volume $1200 \mathrm{ml}$. Standard bypass technique with systemic hypothermia of 28 - 32 degrees celsius was followed. There was a membrane oxygenator in the circuit and the blood flow rate was $2.2-2.4 \mathrm{~L} / \mathrm{min} / \mathrm{m}^{2}$. Mean arterial pressure was maintained between $40-60$ $\mathrm{mm}$ of Hg. Hemoglobin was maintained between $6-8$ $\mathrm{gm} / \mathrm{dl}$. All patients received an inspired oxygen concen- tration of 0.7 during cardiopulmonary bypass. In the normoxic group, the inspired oxygen concentration was lowered to 0.5 from the last warm cardioplegia administration till aortic cross clamp release. The inspired oxygen concentration was again increased to 0.7 . In both the hyperoxic and normoxic groups, arterial blood gas analysis was done after the last warm cardioplegia administration. All patients received nitroglycerine and dobutamine infusion while weaning from cardiopulmonary bypass. All surgeries were done by a single surgeon.

All patients were transferred to the intensive care unit after surgery. Packed red blood cells were transfused when the hematocrit was less than $25 \%$. Hemodynamic variables, including heart rate, mean arterial pressure and central venous pressure were recorded during induction of anesthesia, weaning from cardiopulmonary bypass, sternum closure, 6 hours and 24 hours after surgery. The number of patients requiring inotropes in addition to dobutamine infusion and who developed arrhythmia after reperfusion were noted. Duration of intensive care unit stay and duration of ventilation were recorded. Arterial blood gas was done before going on cardiopulmonary bypass and after reperfusion and release of cross clamp. Blood urea nitrogen and serum creatinine were measured preoperatively, day $1 \& 2$ after surgery.

\section{Statistics}

Power calculation suggested that a minimum of 13 patients per group would detect a $15 \%$ differences in outcome variables between groups after intervention $(\alpha=$ $0.05, \beta=0.2$ ). To take care of any dropouts, we enrolled 15 patients in each group. All data were analyzed by student's $\mathrm{t}$ test (independent samples $t$ test), Chi-square test, Mann-Whitney $U$-test, and Fisher's exact test wherever applicable. The package SPSS 17.0 (SPSS Inc., Chicago, IL, USA) was used for statistical analysis. $p$ value $<0.05$ was considered as statistically significant. All data are expressed as number of patients or mean $+/-$ standard deviation.

\section{Results}

There were no significant differences in the demographic data between the two groups (Table 1). The duration of cardiopulmonary bypass and aortic cross clamp were higher in normoxic group although it was not significant. There is no significant difference in the duration of mechanical ventilation and intensive care unit stay. Additional inotropic requirement and new arrhythmia ater reperfusion was similar in both groups (Table 2). The arterial blood gas analysis after the last warm cardioplegia administration was not significantly different, except for the low oxygen partial pressure in the normoxic group (Table 3). Hydrogen ion concentration, partial 
Table 1. Demographic data.

\begin{tabular}{cccc}
\hline & $\begin{array}{c}\text { Hyperoxic group } \\
(\mathrm{n}=15)\end{array}$ & $\begin{array}{c}\text { Normoxic group } \\
(\mathrm{n}=15)\end{array}$ & P value \\
\hline Age in years & $45.5 \pm 13.5$ & $38.9 \pm 14.0$ & 0.20 \\
No of Males & 5 & 8 & 0.269 \\
No of females & 10 & 7 & 0.62 \\
Height in $\mathrm{cm}$ & $160.5 \pm 7.9$ & $162.9 \pm 10.5$ & 0.47 \\
Weight in $\mathrm{kg}$ & $55.9 \pm 12.9$ & $57.2 \pm 16.6$ & 0.80 \\
BSA in $\mathrm{m}^{2}$. & $1.6 \pm 0.19$ & $1.7 \pm 0.23$ & 0.70 \\
\hline
\end{tabular}

$\mathrm{P}$ value $<0.05$ is considered significant. Values measured in mean \pm standard deviation except the gender. BSA: Body surface area.

Table 2. Duration of CPB, cross clamp time, duration of ventilation, intensive care unit stay and number of patients receiving additional inotropes and who developed arrhythmia.

\begin{tabular}{cccc}
\hline & $\begin{array}{c}\text { Hyperoxic group } \\
(\mathrm{n}=15)\end{array}$ & $\begin{array}{c}\text { Normoxic group } \\
(\mathrm{n}=15)\end{array}$ & $\begin{array}{c}\mathrm{P} \\
\text { value }\end{array}$ \\
\hline CPB duration in minutes & $95.6 \pm 15.6$ & $110.0 \pm 27.8$ & 0.90 \\
$\begin{array}{c}\text { Cross clamp time in } \\
\text { minutes }\end{array}$ & $63.7 \pm 15.9$ & $70.5 \pm 26.6$ & 0.40 \\
$\begin{array}{c}\text { Duration of ventilation } \\
\text { in hours }\end{array}$ & $10.26 \pm 4.28$ & $9.60 \pm 5.05$ & 0.260 \\
$\begin{array}{c}\text { Intensive care unit } \\
\text { stay in days }\end{array}$ & $3.60 \pm 1.54$ & $3.46 \pm 0.83$ & 0.810 \\
$\begin{array}{c}\text { No of patients received } \\
\text { additional inotropes }\end{array}$ & 12 & 12 & 1.00 \\
$\begin{array}{c}\text { No of patients who had } \\
\text { arrhythmia after } \\
\text { reperfusion }\end{array}$ & 7 & 6 & 0.91 \\
\hline
\end{tabular}

CPB: Cardiopulmonary bypass. P value $<0.05$ is considered significant. Values measured in mean \pm standard deviation.

Table 3. Arterial blood gas before cardiopulmonary bypass and after reperfusion.

\begin{tabular}{cccc}
\hline & $\begin{array}{c}\text { Hyperoxic group } \\
(\mathrm{n}=15)\end{array}$ & $\begin{array}{c}\text { Normoxic group } \\
(\mathrm{n}=15)\end{array}$ & P value \\
\hline \multicolumn{4}{c}{ Pre cardiopulmonary bypass } \\
$\mathrm{pH}$ & $7.43 \pm 0.46$ & $7.42 \pm 1.54$ & 0.12 \\
$\mathrm{PO}_{2}(\mathrm{~mm} \mathrm{of} \mathrm{Hg})$ & $182.4 \pm 99.2$ & $178.5 \pm 64.0$ & 0.95 \\
Lactate $(\mathrm{mmol} / \mathrm{L})$ & $1.57 \pm 0.71$ & $1.28 \pm 0.77$ & 0.170 \\
Base excess $(\mathrm{mmol} / \mathrm{L})$ & $0.56 \pm 2.98$ & $0.43 \pm 2.1$ & 0.836 \\
& After reperfusion & & \\
$\mathrm{pH}$ & $7.44 \pm 0.062$ & $7.40 \pm 0.08$ & 0.145 \\
$\mathrm{PO}_{2}(\mathrm{~mm} \mathrm{of} \mathrm{Hg})$ & $342.73 \pm 31.4$ & $223.2 \pm 47.9$ & $0.02^{*}$ \\
Lactate $(\mathrm{mmol} / \mathrm{L})$ & $4.73 \pm 1.17$ & $4.34 \pm 1.67$ & 0.237 \\
$\mathrm{Base}$ excess $(\mathrm{mmol} / \mathrm{L})$ & $-2.09 \pm 2.49$ & $-2.8 \pm 2.40$ & 0.290 \\
\hline
\end{tabular}

${ }^{*} \mathrm{P}$ value $<0.05$ is considered significant. Values measured in mean \pm standard deviation. $\mathrm{pH}$ : Hydrogen ion concentration. $\mathrm{PO}_{2}$ : Partial pressure of oxygen. CPB: Cardiopulmonary bypass.

pressure of oxygen and lactate levels on postoperative day 1 and 2 were similar (Table 4). Blood urea nitrogen and serum creatinine were similar in both groups (Table 5). With regard to hemodynamic variables mean arterial pressure of the hyperoxic group was higher one hour after the cross clamp release. In all other time periods of measurement the hemodynamic variables were comparable (Table 6).

\section{Discussion}

This study was designed to evaluate the effect of arterial oxygen tension during reperfusion on hemodynamics, inotropes in addition to dobutamine, renal function, duration of ventilation, and intensive care unit stay in patients undergoing mitral valve surgery. Valvular heart surgery has the possibility of reducing myocardial function by increasing afterload post-operatively, unlike the coronary artery bypass grafting surgery that improve myocardial function by increased coronary flow. Cardiopulmonary bypass is not only associated with myocardial ischemic injury during aortic cross clamping, but also reperfusion injury after discontinuation of cross clamp [10]. It is clinically important to find a method that reduces myocardial injury from ischemic-reperfusion for patients undergoing valvular heart surgery. Reduced oxygen tension during reperfusion after aortic unclamping on cardiopulmonary bypass is more effective against myocardial injury than a calcium antagonist in the short term [1]. It is a convenient and safe management technique that can reduce morbidity and mortality, especially in the severely compromised heart.

There is major increase in oxygen free radicals due to reperfusion with oxygenated blood. Free radicals such as superoxide $\left(\mathrm{O}_{2}\right)$, hydroxyl $\left(\mathrm{OH}^{-}\right)$and hydrogen peroxide $\left(\mathrm{H}_{2} \mathrm{O}_{2}\right)$ are extremely reactive and indistinctly damage all cell components, increasing ischemia-induced cell injuries [11]. The production of these free radicals is proportionate to oxygen tension $\left(\mathrm{PO}_{2}\right)$ during reperfusion [12]. Clinical consequences may go from reversible myocardial dysfunction persisting after reperfusion and known as myocardial stunning, to myocardial infarction. So in our study instead of looking at biomarkers of myocardial injury we looked at clinical outcomes like increased inotropes requirement and duration of ventilation.

During adult cardiac surgery, cardiopulmonary bypass is commonly hyperoxic and can itself also lead to the production of oxygen-derived free radicals [13]. Studies have free radical scavengers improves the recovery of cardiac function following preservation and reperfusion [14]. The present study showed that lowering the oxygen concentration during reperfusion after aortic unclamping did not affect the outcomes in terms of additional inotrope requirement, duration of mechanical ventilation or intensive care unit stay. The concept of reperfusion injury remains controversial with several proposed mechanisms, but it is mainly oxygen-derived free radicals and 
Table 4. Arterial blood gas $1^{\text {st }}$ and $2^{\text {nd }}$ postoperative day.

\begin{tabular}{cccc}
\hline & $\begin{array}{c}\text { Hyperoxic group } \\
(\mathrm{n}=15)\end{array}$ & $\begin{array}{c}\text { Normoxic group } \\
(\mathrm{n}=15)\end{array}$ & P value \\
\hline \multicolumn{4}{c}{ Postoperative day 1} \\
$\mathrm{pH}$ & $7.38 \pm 0.06$ & $7.37 \pm 0.05$ & 0.950 \\
$\mathrm{PO}_{2}(\mathrm{~mm}$ of $\mathrm{Hg})$ & $169.7 \pm 58.1$ & $161.6 \pm 59.6$ & 0.619 \\
Lactate $(\mathrm{mmol} / \mathrm{L})$ & $2.51 \pm 1.42$ & $2.09 \pm 0.923$ & 0.493 \\
Base excess $(\mathrm{mmol} / \mathrm{L})$ & $0.593 \pm 2.46$ & $0.08 \pm 2.03$ & 0.372 \\
& Postoperative day 2 & \\
$\mathrm{pH}$ & $7.42 \pm 0.04$ & $7.39 \pm 0.06$ & 0.297 \\
$\mathrm{PO}_{2}(\mathrm{~mm} \mathrm{of} \mathrm{Hg})$ & $111.5 \pm 71.05$ & $123.8 \pm 69.2$ & 0.290 \\
$\mathrm{Lactate}(\mathrm{mmol} / \mathrm{L})$ & $1.11 \pm 0.408$ & $1.15 \pm 0.86$ & 0.404 \\
$\mathrm{Base}$ excess $(\mathrm{mmol} / \mathrm{L})$ & $1.84 \pm 3.52$ & $0.42 \pm 3.67$ & 0.329 \\
\hline
\end{tabular}

$\mathrm{P}$ value $<0.05$ is considered significant. Values measured in mean \pm standard deviation. $\mathrm{pH}$ : Hydrogen ion concentration. $\mathrm{PO}_{2}$ : Partial pressure of oxygen. ABG: Arterial blood gas.

Table 5. Blood urea nitrogen and creatinine values.

\begin{tabular}{cccc}
\hline & $\begin{array}{c}\text { Hyperoxic group } \\
(\mathrm{n}=15)\end{array}$ & $\begin{array}{c}\text { Normoxic group } \\
(\mathrm{n}=15)\end{array}$ & P value \\
\hline \multicolumn{4}{c}{ Preoperative } \\
Blood urea nitrogen & $11.8 \pm 3.22$ & $13.13 \pm 4.13$ & 0.441 \\
Creatinine & $0.87 \pm 0.15$ & $0.946 \pm 0.26$ & 0.689 \\
& Postoperative day one & \\
Blood urea nitrogen & $13.8 \pm 4.85$ & $14.5 \pm 3.92$ & 0.338 \\
Creatinine & $0.96 \pm 0.27$ & $1.13 \pm 0.28$ & 0.103 \\
& Postoperative day two & \\
Blood urea nitrogen & $15.2 \pm 4.90$ & $15.8 \pm 6.80$ & 0.967 \\
Creatinine & $0.89 \pm 0.38$ & $0.96 \pm 0.33$ & 0.390 \\
\hline
\end{tabular}

$\mathrm{P}$ value $<0.05$ is considered significant. Values measured in mean \pm standard deviation. Values are given in $\mathrm{mg} / \mathrm{dl}$.

calcium overload that play an important role in the development of left ventricular dysfunction, stunning, reperfusion arrhythmias, vascular damage, and endothelial dysfunction [15].

Various strategy used to reduce ischemic-reperfusion injury include lowering blood pressure during reperfusion, reducing blood flow during reperfusion, but one of the most vigorously researched methods is controlling arterial oxygen tension in order to reduce reperfusion injury [16-18]. Maintaining normoxic cardiopulmonary bypass in children with cyanotic congenital heart disease resulted in dramatically reduced levels of conjugated diens, which represents the lipid peroxidation levels of the heart, compared with patients that maintained on hyperoxic cardiopulmonary bypass [19]. Also there is a reduced levels of creatinine kinase-myocardial bound, a biomarker indicating the extent of myocardial damage, in adult patients in which arterial oxygen tension was maintained in the normal range tension during cardiopulmon-
Table 6. Changes in hemodynamic parameters.

\begin{tabular}{|c|c|c|c|}
\hline & $\begin{array}{l}\text { Hyperoxic group } \\
\quad(\mathrm{n}=15)\end{array}$ & $\begin{array}{l}\text { Normoxic group } \\
\quad(\mathrm{n}=15)\end{array}$ & $P$ value \\
\hline \multicolumn{4}{|c|}{ Post induction } \\
\hline HR (beats/min) & $85.73 \pm 15.21$ & $82.60 \pm 14.28$ & 0.868 \\
\hline MAP (mm of $\mathrm{Hg})$ & $77.60 \pm 11.6$ & $70.20 \pm 11.07$ & 0.140 \\
\hline CVP (mm of Hg) & $7.86 \pm 3.20$ & $8.20 \pm 3.07$ & 0.544 \\
\hline \multicolumn{4}{|c|}{1 hour after unclamping of aorta } \\
\hline HR (beats/min) & $107.71 \pm 13.50$ & $107.33 \pm 20.46$ & 0.693 \\
\hline MAP (mm of $\mathrm{Hg}$ ) & $74.60 \pm 10.64$ & $68.0 \pm 10.24$ & $0.042^{*}$ \\
\hline CVP (mm of $\mathrm{Hg}$ ) & $8.0 \pm 2.69$ & $6.86 \pm 2.55$ & 0.306 \\
\hline \multicolumn{4}{|c|}{ After sternal closure } \\
\hline HR (beats/min) & $115.0 \pm 19.44$ & $115.0 \pm 16.36$ & 0.935 \\
\hline MAP (mm of $\mathrm{Hg}$ ) & $79.40 \pm 10.49$ & $76.60 \pm 10.90$ & 0.345 \\
\hline CVP (mm of Hg) & $7.73 \pm 2.49$ & $7.0 \pm 2.36$ & 0.389 \\
\hline \multicolumn{4}{|c|}{6 hours after surgery } \\
\hline HR (beats/min) & $112.0 \pm 21.32$ & $114.06 \pm 13.32$ & 0.567 \\
\hline MAP (mm of $\mathrm{Hg}$ ) & $79.20 \pm 11.88$ & $79.40 \pm 9.96$ & 0.713 \\
\hline CVP (mm of Hg) & $6.06 \pm 2.96$ & $5.46 \pm 2.13$ & 0.744 \\
\hline \multicolumn{4}{|c|}{24 hours after surgery } \\
\hline HR (beats/min) & $108.06 \pm 13.31$ & $102.66 \pm 11.33$ & 0.367 \\
\hline MAP (mm of $\mathrm{Hg})$ & $81.633 \pm 12.61$ & $83.2 \pm 9.97$ & 0.512 \\
\hline CVP (mm of Hg) & $4.73 \pm 1.75$ & $5.26 \pm 2.89$ & 0.775 \\
\hline
\end{tabular}

${ }^{*} \mathrm{P}$ value $<0.05$ is considered significant. Values measured in mean \pm standard deviation. HR: Heart rate. MAP: Mean arterial pressure. CVP: Central venous pressure.

ary bypass and reperfusion [1]. Not only biomarkers there is also better recovery of cardiac function and effective improvement of aortic and coronary blood flow when arterial oxygen tension is maintained between 200 and $250 \mathrm{mmHg}$ when compared with arterial oxygen tension of 400 and $450 \mathrm{mmHg}$ [18]. We reduced the inspired oxygen concentration of reperfusate to 0.5 for a brief period however none of the clinical outcome parameters were altered.

In this study patient characteristics were comparable. There is no significant difference in cardiopulmonary bypass duration and aortic occlusion time between the two groups. Partial pressure of oxygen in normoxic group was low after reperfusion with subsequent values similar to those of hyperoxic group and not statistically significant. There was no significant difference in hemodynamic variables between the two groups except that normoxic group had low blood pressure one hour after aortic cross clamp removal, which was statistically significant. The study done by Jeong-Soo Lee [20] had similar findings but he included all valvular heart disease. In our study we included only severe mitral stenosis with valve area less than $1 \mathrm{~cm}^{2}$, with moderate to several pulmonary hypertension and good biventricular function. 
This eliminated the bias having different subgroup of patients.

It is possible to include other markers of ischemia/ reperfusion injury, such as apoptosis, autophagy, and release of biochemical markers. However, necrosis is the "hardest" end point and the other markers are usually in parallel with necrosis. Thus, hyperoxygenation during very early reperfusion might be damaging. This study however showed that oxygen at the time of reperfusion is not detrimental. If any effect was found, it was that hyperoxia was preventive against lethal ventricular fibrillation. The border zone or the area at risk is critical for generation of reperfusion arrhythmias, and improved oxygenation of this area might be preventive toward lethal arrhythmias. Pre-treatment with hyperoxic gas has a precondition-like, cardioprotective effect, possibly by a nuclear factor-kappa B (NFkB)-dependent mechanism [21]. Heart rate, mean arterial pressure and central venous pressure were not altered by reducing the oxygenation during reperfusion. Also the onset of new arrhythmia during reperfusion was not different between the two groups.

At present we should strive to ensure that oxygen is prescribed, administered, and monitored with care. This will enable us to achieve optimal tissue oxygenation for more of our patients. The important message from our study is that hyperoxia during reperfusion is not detrimental. This is in contrast with studies which have been conducted in animal models on cardiopulmonary bypass [22]. Consequently, increased availability of oxygen during early reperfusion is not harmful.

\section{Conclusion}

Inotropes usage, new arrhythmia after reperfusion, renal function, duration of ventilation and intensive care unit stay were not significantly altered by reducing the oxygen concentration during reperfusion. In the hyperoxic group, the partial pressure of oxygen after reperfusion and blood pressure for 1 hour after aortic cross clamp removal were significantly altered with no clinical avail. By reducing the oxygen concentration during reperfusion, the biomarkers of reperfusion may be reduced; however, the clinical outcomes in terms of inotropes usage, new arrhythmia after reperfusion, renal function, duration of ventilation and intensive care unit stay were not significantly altered.

\section{REFERENCES}

[1] K. Ihnken, A. Winkler, C. Schlensak, K. Sarai, G. Neidhart and U. Unkelbach, "Normoxic Cardiopulmonary Bypass Reduces Oxidative Myocardial Damage and Nitric Oxide during Cardiac Operations in the Adult," The Journal of Thoracic and Cardiovascular Surgery, Vol. 116, No. 2, 1998, pp. 327-334.
http://dx.doi.org/10.1016/S0022-5223(98)70134-5

[2] D. M. Yellon and D. J. Hausenloy, "Myocardial Reperfusion Injury," The New England Journal of Medicine, Vol. 357, No. 11, 2007, pp. 1121-1135. http://dx.doi.org/10.1056/NEJMra071667

[3] W. Ganz, R. Donoso, H. Marcus and H. J. Swan, "Coronary Hemodynamics and Myocardial Oxygen Metabolism during Oxygen Breathing in Patients with and without Coronary Artery Disease," Circulation, Vol. 45, 1972, pp. 763-768. http://dx.doi.org/10.1161/01.CIR.45.4.763

[4] K. Ihnken, K. Morita, G. Buckberg, B. Winkelmann, F. Beyersdorf and M. Sherman, "Reduced Oxygen Tension during Cardiopulmonary Bypass Limits Myocardial Damage in Acute Hypoxic Immature Piglet Hearts," European Journal Cardio-Thoracic Surgery, Vol. 10, No. 12, 1996, pp. 1127-1134. http://dx.doi.org/10.1016/S1010-7940(96)80361-7

[5] T. Inoue, K. Ku, T. Kaneda, Z. Zang, M. Otaki and H. Oku, "Cardioprotective Effects of Lowering Oxygen Tension after Aortic Unclamping on Cardiopulmonary Bypass during Coronary Artery Bypass Grafting," Circulation Journal, Vol. 66, No. 8, 2002, pp. 718-722. http://dx.doi.org/10.1253/circj.66.718

[6] K. Morita and K. Ihnken, "Studies of Hypoxemic/Reoxygenation Injury: With Aortic Clamping: XII. Delay of Cardiac Reoxygenation Damage in the Presence of Cyanosis: A New Concept of Controlled Cardiac Reoxygenation," The Journal of Thoracic and Cardiovascular Surgery, Vol. 110, No. 4, 1995, pp. 1265-1273. http://dx.doi.org/10.1016/S0022-5223(95)70013-7

[7] R. J. Korthuis, J. K. Smith and D. L. Carden, "Hypoxic Reperfusion Attenuates Postischemic Microvascular Injury," American Journal of Physiology, Vol. 256, 1989, pp. H315-319.

[8] M. A. Perry and S. S. Wadhwa, "Gradual Reintroduction of Oxygen Reduces Reperfusion Injury in Cat Stomach," American Journal of Physiology, Vol. 254, 1988, pp. G366-372.

[9] A. J. Thomson, D. J. Webb and S. R. J. Maxwell, "Oxygen Therapy in Acute Medical Care," British Medical Journal, Vol. 324, 2002, pp. 1406-1407.

http://dx.doi.org/10.1136/bmj.324.7351.1406

[10] D. J. Cook, P. R. Housmans and K. H. Rehfeldt, "Valvular Heart Disease-Replacement and Repair. Kaplan's Cardiac Anesthesia," 5th Edition, Elsevier, Inc., Philadelphia, 2006, pp. 645-690.

[11] Y. Gauduel, P. Menasche and M. Duvelleroy, "Enzyme release and Mitochondrial Activity in Reoxygenated Cardiac Muscle: Relationship with Oxygen-Induced Lipid Peroxidation," General Physiology Biophysics, Vol. 8, No. 4, 1989, pp. 327-340.

[12] A. Littauer and H. de Groot, "Release of Reactive Oxygen by Hepatocytes on Reoxygenation: Three Phases and Role of Mitochondria," American Journal of Physiology, Vol. 262, 1992, pp. G1015-G1020.

[13] K. Prasad, W. P. Chan and B. Bharadwaj, "Superoxide Dismutase and Catalase in Protection of Cardiopulmonary Bypass-Induced Cardiac Dysfunction and Cellular Injury," Canadian Journal of Cardiology, Vol. 12, 1996, 
pp. 1083-1091.

[14] K. Ku, S. Kin, M. Hashimoto, Y. Saitoh, S. Nosawa and S. Iwasaki, "The Role of a Hydroxyl Radical Scavenger (Nicaraven) in Recovery of Cardiac Function Following Preservation and Reperfusion," Transplantation, Vol. 62, No. 8, 1996, pp. 1090-1095. http://dx.doi.org/10.1097/00007890-199610270-00012

[15] L. H. Opie, "Reperfusion Injury and Its Pharmacologic Modification," Circulation, Vol. 80, 1989, pp. 10491062. http://dx.doi.org/10.1161/01.CIR.80.4.1049

[16] J. C. Bopassa, P. Michel, O. Gateau-Roesch, M. Ovize and R. Ferrera, "Low-Pressure Reperfusion Alters Mitochondrial Permeability Transition," American Journal of Physiology-Heart and Circulatory Physiology, Vol. 288, 2005, pp. H2750-2755. http://dx.doi.org/10.1152/ajpheart.01081.2004

[17] S. Takeo, J. X. Liu, K. Tanonaka, Y. Nasa, K. Yabe, H. Tanahashi, et al., "Reperfusion at Reduced Flow Rates Enhances Postischemic Contractile Recovery of Perfused Heart," American Journal of Physiology, Vol. 268, 1995, pp. H2384-2395.

[18] T. Inoue, K. Ku, T. Kaneda, Z. Zang, M. Otaki and H. Oku, "Cardioprotective Effects of Lowering Oxygen Tension after Aortic Unclamping on Cardiopulmonary Bypass during Coronary Artery Bypass Grafting," Circula- tion Journal, Vol. 66, No. 8, 2002, pp. 718-722. http://dx.doi.org/10.1253/circj.66.718

[19] P. J. del Nido, D. A. Mickle, G. J. Wilson, L. N. Benson, J. G. Coles, G. A. Trusler, et al., "Evidence of Myocardial free Radical Injury during Elective Repair of Tetralogy of Fallot," Circulation, Vol. 76, 1987, pp. V174-179.

[20] J.-S. Lee, J.-C. Kim, J.-Y. Chung, S.-W. Hong, K.-H. Cho and Y. L. Kwak, "Effect of Arterial Oxygen Tension during Reperfusion on Myocardial Recovery in Patients Undergoing Valvular Heart Surgery," Korean Journal of Anesthesiology, Vol. 58, No. 2, 2010, pp. 122-128. http://dx.doi.org/10.4097/kjae.2010.58.2.122

[21] P. Tähepold, J. Vaage, J. Starkopf and G. Valen, "Hyperoxia Elicits Myocardial Protection through a Nuclear Factor kappaB-Dependent Mechanism in the Rat Heart," The Journal of Thoracic and Cardiovascular Surgery, Vol. 125, No. 3, 2003, pp. 650-660. http://dx.doi.org/10.1067/mtc.2003.36

[22] K. Ihnken, K. Morita, G. Buckberg, B. Winkelmann, F. Beyersdorf and M. Sherman, "Reduced Oxygen Tension during Cardiopulmonary Bypass Limits Myocardial Damage in Acute Hypoxic Immature Piglet Hearts," European Journal Cardio-Thoracic Surgery, Vol. 10, No. 12, 1996, pp. 1127-1134.

http://dx.doi.org/10.1016/S1010-7940(96)80361-7 